\title{
Numerical Simulation of Fractal Interface Effect of Mining-Caused Activation of Fault
}

\author{
YU GUANGMING ${ }^{\mathrm{a}, *}$, ZHAO JIANFENG ${ }^{\mathrm{a}}$ and XIE HEPING $^{\mathrm{b}}$ \\ ${ }^{\mathrm{a}}$ The Postgraduate Department, Liaoning Technical University, Fuxin, Liaoning Province, 123000 People's Republic of China; ${ }^{\mathrm{b}}$ China University of \\ Mining and Technology, Beijing, People's Republic of China
}

(Received 6 April 2001)

\begin{abstract}
Mining-caused activation of fault is an important research subject in mining science. In the past, the influences of geometrical morphology of fault surface on the activation have not been revealed. In view of the fractal character of fault surface, the self-affine fractal curves and geological-mining models with these kinds of fractal fault surface are constructed in order to numerically simulate the mining-caused activation phenomenon of fractal fault surface, and the law of influence of fractal fault surface on mining subsidence is studied and summarized. Our study shows that the mining-cased activation of fault has remarkable fractal interface effect; the mechanical behavior of mining-caused shearing sliding of fault is correlated with its fractal dimension, and after mining-caused activation fault surface with different fractal dimensions will result in different stress fields and different displacement fields in the nearby rock mass.
\end{abstract}

Keywords: Mining-caused activation of fault; Fractal interface effect; Fractal dimension; Geologicalmining models

Mining-caused activation of fault (joint) is a typical nonlinear mechanical problem in mining subsidence subject. It refers to the mining-caused sliding phenomenon of fault (joint) in rock mass. Faults (joints) exist extensively in coal-bearing stratum. Between the hanging wall and foot wall of some faults there are filling materials, and in some faults there are not or only a few filling materials. For the latter, its mining-caused shearing sliding mechanical character is obviously controlled by the geometrical morphology of fault (joint) surface. But in previous researches the fault surfaces were always be considered as smooth surfaces and such a consideration clearly does not tally with real situation. It has been showed by studies (Xie, 1993; Xie and Pariseau, 1994; Yu et al., 1996; Xie et al., 1997a,b) that geological fracture plane is self-affine fractal (Falconer, 1990; Ran, 1994; Xie and Zhao, 1996; Xie and Yu, 1998). It has been proved by experiments that there is remarkable correlation between the shearing mechanical behavior of rock mass fracture plane and its fractal dimension (Xie, 1996; Yu, 1997; Yu and Yang, 2000). Therefore by means of numerical simulation we study, test and verify the correlation between mining-caused shearing sliding behavior of fault (joint) and its fractal dimension, and summarize the law of influence of fractal dimension on mining subsidence.

\section{BASIC WORKS OF NUMERICAL SIMULATION}

By means of Weaerstrass-Mandelbrot function the selfaffine curve is constructed, and the function expression is:

$$
w(t)=\sum_{n=-\infty}^{\infty}\left(1-\mathrm{e}^{\mathrm{i} b^{n} t}\right) \mathrm{e}^{\mathrm{i} \phi_{n}} / b^{(2-D) n}
$$

Let $\Phi n=0, b=1.5$ and suppose it is a sine function, then the following equation can be obtained:

$$
f(t)=\sum_{n=0}^{\infty}\left(\frac{3}{2}\right)^{(D-2) n} \sin \left(\frac{3}{2}\right)^{n} t
$$

where $D$ is self-affine fractal dimension, $D \in[1,2]$.

Let $D=1.1,1.2,1.3,1.4$, and 1.5 , respectively to construct five self-affine fractal curves and these five curves are preset into five geological-mining simulation prototypes. The conditions of these simulation prototypes are: thickness of coal seam's overburden $50 \mathrm{~m}$, thickness of coal seam's floor $10 \mathrm{~m}$, total stratum thickness $60 \mathrm{~m}$, strike length $200 \mathrm{~m}$, coal seam is horizontal, mining thickness $1.6 \mathrm{~m}$, lithology of the whole stratum is uniform sandstone, fault's dip angle $65^{\circ}$, and the goaf is situated on the hanging side of fault. During the entire calculation

*Corresponding author. 

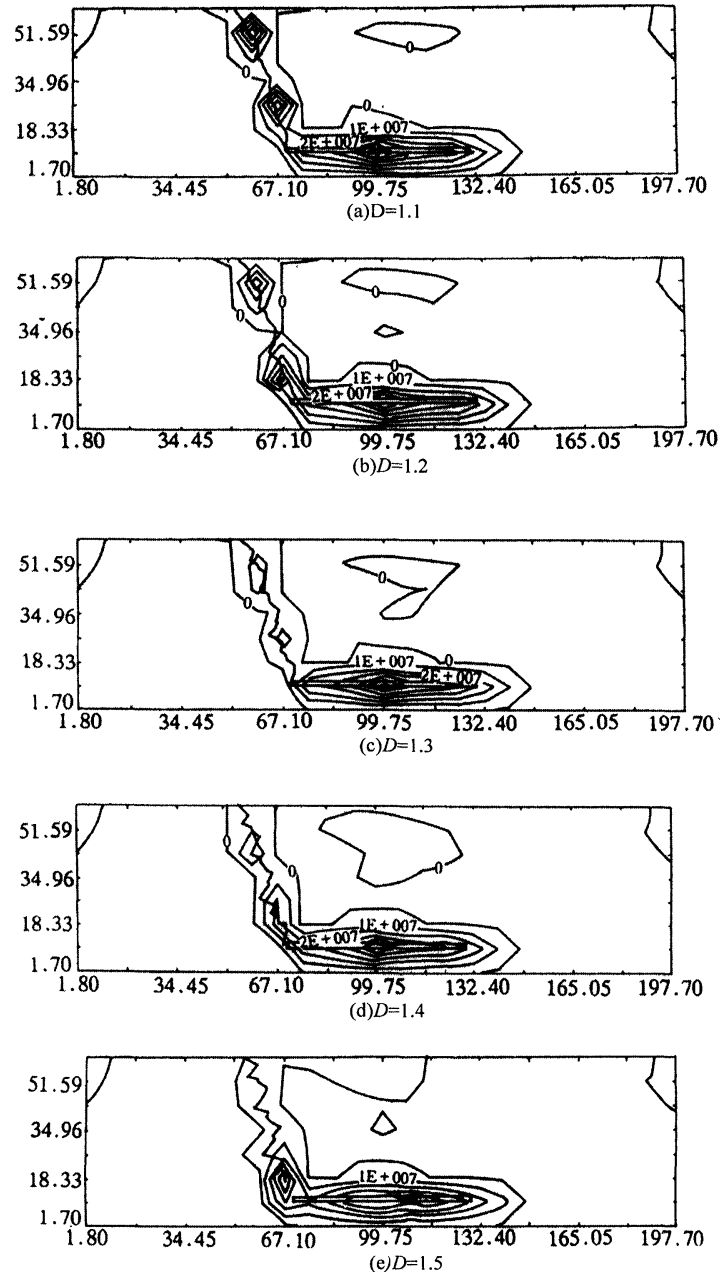

FIGURE 1 Distribution of tensile stresses in the $Y$ direction. In this figure, the unit of stress is: $10^{5} \mathrm{~Pa}$.

process, all parameters except the dimensions $(D=1.1$, $1.2,1.3,1.4$, and 1.5) maintain unchanged so as to make a through inquiry about the different distribution patterns of surface subsidence, horizontal displacement and stress above goaf when different fractal faults with various dimensions $(D=1.1,1.2,1.3,1.4$, and 1.5) are involved under the influence of underground mining. The mining is carried out in tow steps: firstly $40 \mathrm{~m}$ are mined from left to right; then the working face continually proceeds to $60 \mathrm{~m}$ (Figs. 1 and 2) (Yu, 1997).

\section{ANALYSIS OF THE NUMERICAL SIMULATION RESULTS OF MINING-CAUSED FAULT'S FRACTAL INTERFACE EFFECT}

\subsection{The Influence of Fractal Fault Surface on the Stress Distribution and Disruption Law of Rock Mass}

Through simulation, the stress distribution in coal seam's overburden, the conditions of overburden disruption and surface subsidence after mining are acquired. When mining width is $40 \mathrm{~m}$, the influence of mining does not
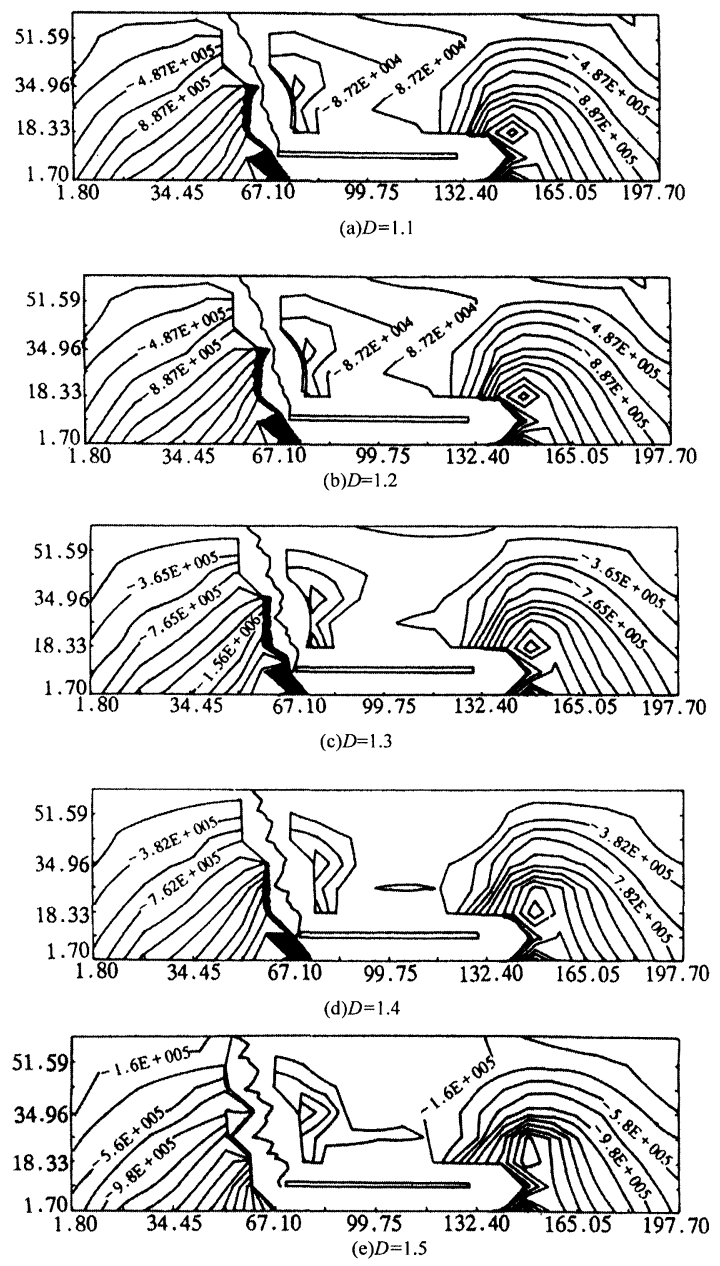

FIGURE 2 Distribution of compressive stresses in $Y$ direction. In this figure, the unit of stress is: $10^{5} \mathrm{~Pa}$.

lead to activation of fault surface, the stress distribution and overburden disruption conditions of all the five models are basically the same, that is to say, in the overburden close to the goaf there are two-way tensile disruption, and caving zone is formed and develops upward to become one-way (vertical) tension, thus it is easy to result in separation layer.

While above the coal pillars lying on both sides of goaf there is a literal-tension and vertical-compression bearing pressure zone. On both sides of goaf the distributions of compressive stress are roughly symmetrical and their patterns are basically same. Near the border of surface subsidence trough, inside the rock mass there is a lateraltension and vertical-compression boundary disruption zone where ground fractures can appear easily. The displacement distribution of ground points maintains normal, and on both sides of the fault the deformations of models' nodes are continuous.

When mining width reaches $60 \mathrm{~m}$, the influences of mining spread to entire fractal fault surface and on all the five models nearby the fractal fault surface the stress concentration phenomena appear, but these phenomena are different because of the difference of fractal dimensions of fault surface. In order to make it more 
clear, we decompose the stress distribution into tensile stress distributions and compressive stress distributions in $X$ and $Y$ directions as shown in Figs. 1 and 2. From the stress distribution situations of the five models, it can be seen that the influence of fault surface's fractal geometrical morphology on the tensile stress in $Y$ direction is not big, but the stress value in tensile zone is bigger than the stress value when mining width is $40 \mathrm{~m}$. The compressive stress distribution varies with the geometrical morphology of fault surface: as the fractal dimension increases the concentration degree of compressive stress in $X$ direction near ground surface decreases gradually, it means the activation of fault becomes less and less resulting the gradually decrease of contact degree of rock mass of fault's two walls. At the lower part of fractal fault surface, the concentration degree of tensile stress in $Y$ direction is roughly same, while at the upper part as the fractal dimension increases the concentration degree becomes smaller and smaller, it means the up-and-down morphology of fault surface has certain influence on the tensile stress of rock mass in $Y$ direction. Due to the influence of mining, the fault surface is activated, as the fractal dimension increases the occlusion between rock mass of fault's two walls becomes bigger and bigger, and during the process of fault's activation the resistance increases gradually, therefore the displacement value of lower rock mass and the upward transmitting amount of displacement decreases gradually, thus resulting the concentration degree above fault surface decreases gradually. As the fractal dimension increases, the extent of compressive zone of rock mass right above goaf extends and the position of tensile zone ascends, it means the tensile disruption (separation layer) zone ascends higher and higher, it tallies with the experimental

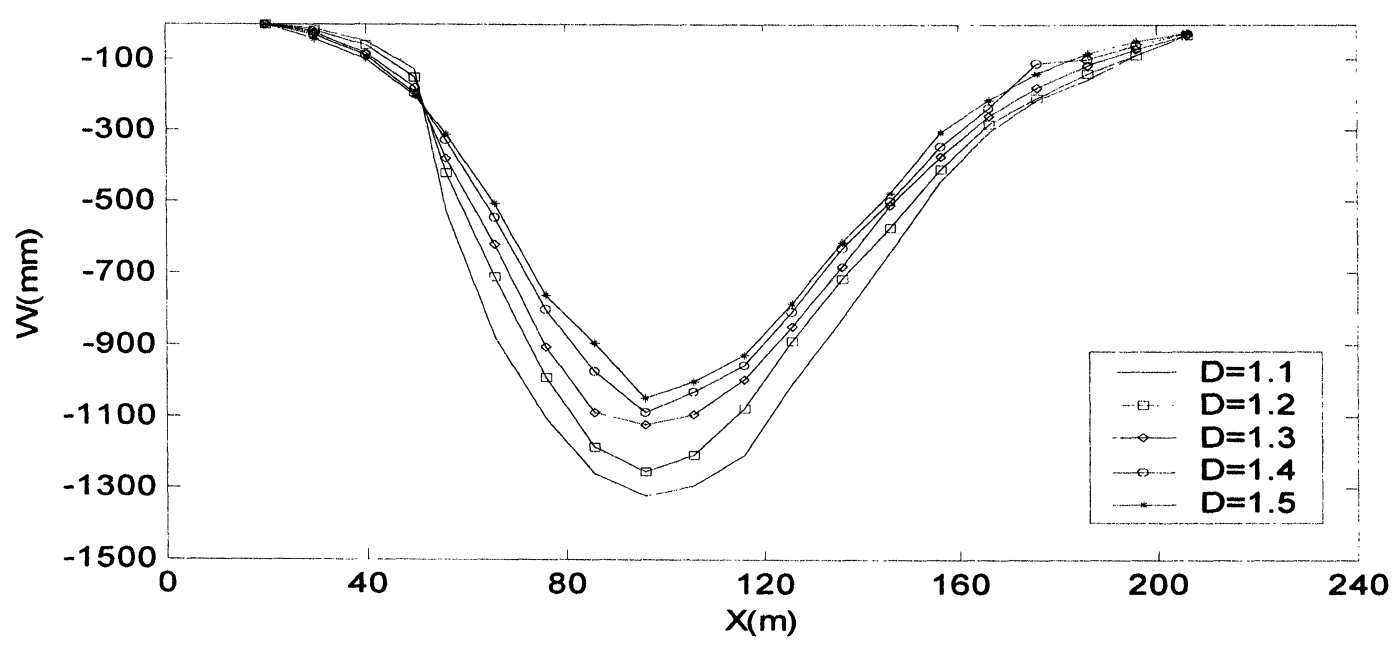

(a)Subsidence

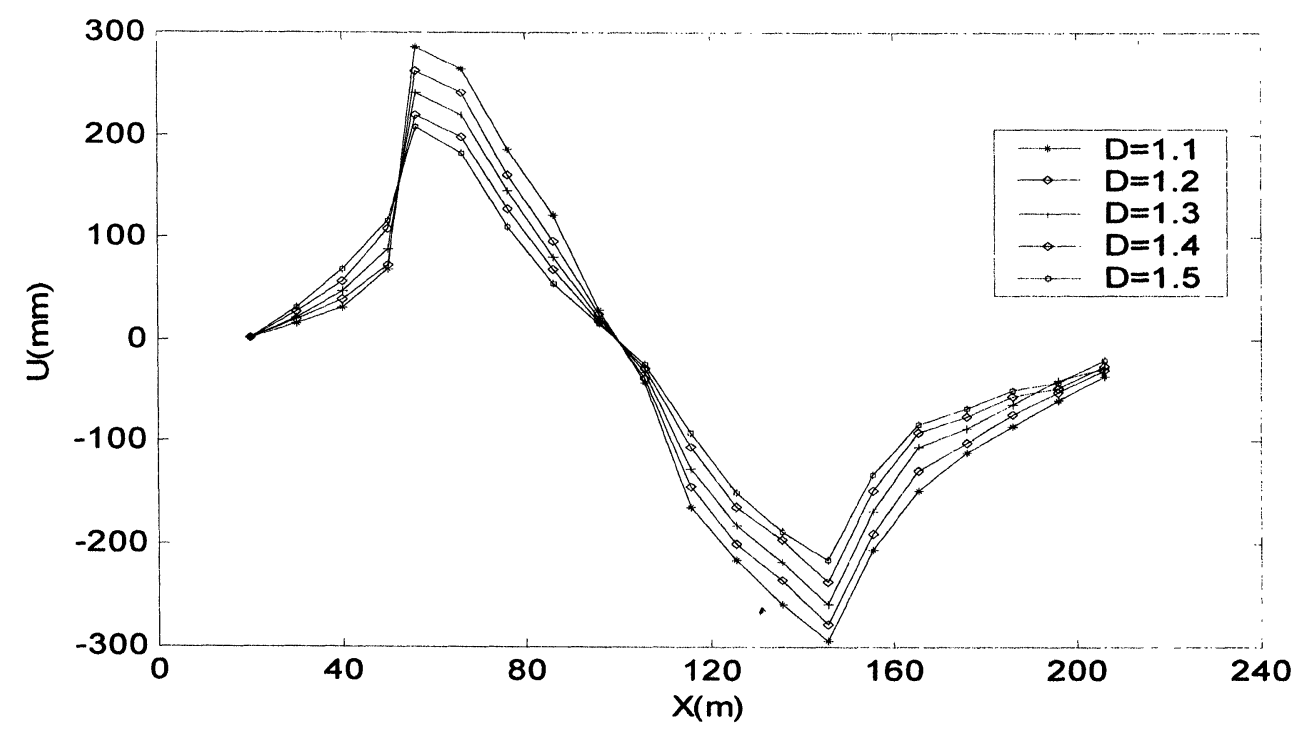

(b) Horizontal movement

FIGURE 3 Curves of earth surface movement 1,2,3, 4, and 5 represent $D=1.1,1.2,1.3,1.4$, and 1.5, respectively. 
TABLE I Simulation of drop height of steps of fault's two sides and the maximum subsidence

\begin{tabular}{lccccc}
\hline Number of model & 1 & 2 & 3 & 4 & \multicolumn{1}{c}{5} \\
\hline$D$ & 1.1 & 1.2 & 1.3 & 1.4 & 1.5 \\
$H(\mathrm{~mm})$ & 350 & 226 & 140 & 89 & 34 \\
$W_{\mathrm{m}}(\mathrm{mm})$ & 1350 & 1260 & 1140 & 1050 & 930 \\
\hline
\end{tabular}

results. It can be seen from Figs. 1 and 2 that as the fractal dimension increases the height of rock mass tensile zone right above goaf does not change remarkably, it means the height of caving zone does not change when fractal dimension of fault surface changes. The height of separate layer zone increases when the fractal dimension increases, this also tallies with the experimental results. As the fractal dimension increases, the rock mass compression in stope's entire overburden decreases gradually, this is mainly because as the fractal dimension increases the vertical displacement of overburden rock mass decreases, and the main compressive stress also shows the same changing pattern, this tallies with experimental results relatively well.

When mining width is $60 \mathrm{~m}$, the rock mass disruption condition also shows different pattern. In the models the smaller the fractal dimension of fault surface, the bigger the tensile zone and tension near fault surface, resulting more serious disruption and the more acute activation of fault.

\subsection{The Influence of Fractal Fault Surface on the Law of Surface Movement}

Through numerical simulation, under the condition of mining influence spreading to fractal fault surface, the earth surface movement values are obtained (Fig. 3), and the drop height of earth surface steps and the maximum subsidence are also sorted out (Table I).

From the results of earth surface movement, it can be seen that the fractal fault surfaces have remarkable influence on the law of earth surface movement. The movement values of survey points located at different sides of fault are not continuous, and steps appear at the outcrop of fault but their drop heights are different. As the fractal dimension increases, the drop height of step decreases gradually and the earth surface subsidence also decreases. Figures 4 and 5 are the regression curves of the relation between $H$ (drop height) and $D$ (fractal dimension), and between $W_{\mathrm{m}}$ (maximum subsidence and $D$, respectively. From these curves the changing law of $H$, $W_{\mathrm{m}}$ and $D$ can be seen clearly.

\section{CONCLUSIONS}

The activation of fault is controlled by the fractal morphology of fault surface. The law of influence of fractal character on the stress distribution within rock mass after mining is as follows: the influence of fractal

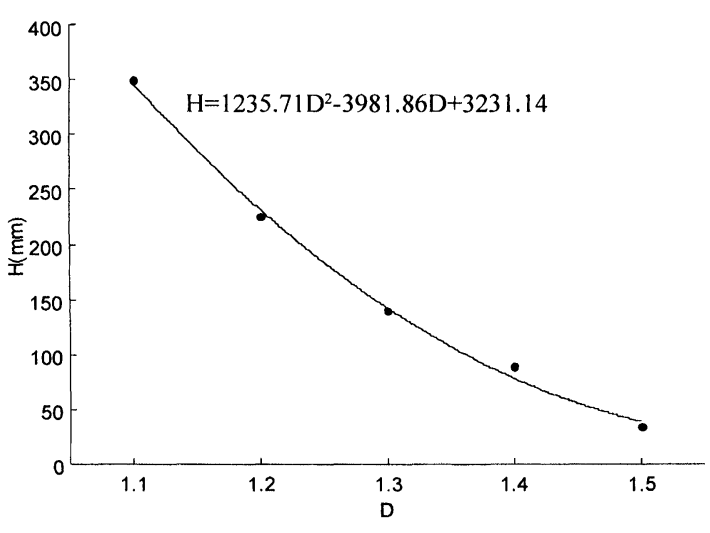

FIGURE 4 Relation between $H$ and $D$.

character of fault surface on the tensile stress in $X$ direction is not remarkable. When the fractal dimension changes, below fault surface the concentration degree of compressive stress in $X$ direction and the tensile stress in $Y$ direction do not change. When the fractal dimension increases, near the outcrop of fault the concentration degree becomes less and less, it means the activation degree of fault becomes smaller and smaller, resulting in the decrease of contact degree between rock mass of fault's two sides. When the fractal dimension of fault surface increases, the compressive stress of entire overburden above stope decreases gradually, it means as the fractal dimension of fault surface increases the mutual restrain between rock mass located at fault's two sides increases, resulting in the decrease of downward movement of stope's overburden and the increase of separation layers.

Under the conditions of our research, the experimental numerical relations between $H$ (drop height of steps), $W_{\max }$ (the maximum subsidence) and $D$ (fractal dimension of fault surface) are as follows:

$$
\begin{aligned}
H & =1235.71 D^{2}-3981.86 D+3231.14, \quad W_{\max } \\
& =-214.29 D^{2}-492.86 D+2153.14 .
\end{aligned}
$$

Through numerical simulation research of miningactivated fault fractal interface, the fractal interface effect

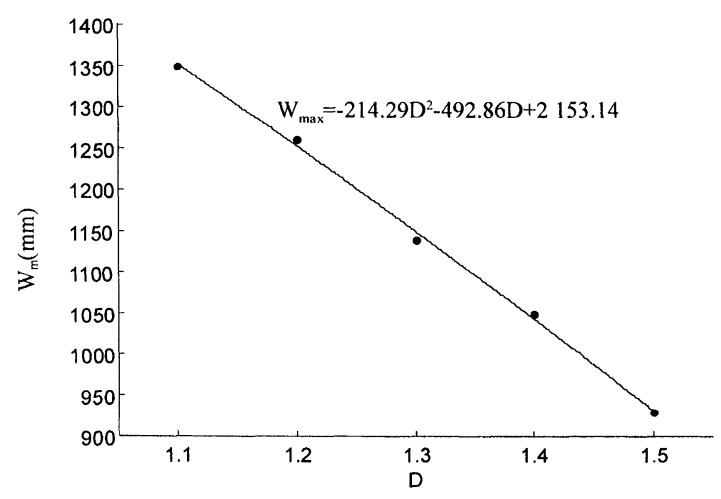

FIGURE 5 Relation between $W_{\mathrm{m}}$ and $D$. 
in the hanging wall and heading wall of structural surface of engineering rock mass is revealed, the law of influence of fractal character of fault surface on rock mass disruption and earth surface subsidence is obtained. These achievements of research have certain theoretical value for deep study of the mechanism of mining-caused activation of fault, are of great engineering significance for prediction of mining-caused activation degree of fault, the discontinuous subsidence and the disruption degree of underground and surface engineering facilities which straddle fault, and supply reliable theoretical basis for the control of mining-caused activation of fault.

\section{References}

Falconer, K. (1990) Fractal Geometry: Mathematical Foundations and Applications (John and Sons Ltd., England).

Ran, J.Q. (1994) "Shear sliding failure of the jointed roof in laminated rock mass", Rock Mech. Rock Engng 27(4), 235-251.
Xie, H. (1993) Fractals in rock mechanics (Balkema, Rotterdam).

Xie, H. (1996) Fractal Rock Mechanics Guide (Science Publishing House, Beijing), pp 262-358.

Xie, H. and Pariseau, W.G. (1994) "Estimation of rock joint roughness coefficient (JRC) fractal", China Sci. B Ed. 24(5), 524-530.

Xie, H. and Yu, G. (1998) "The influence of proximate fault morphology on ground subsidence due to extraction", Int. J. Rock Mech. Min. Sci. Geomech. Abstr. 35(8), 1107-1111.

Xie, H. and Zhao, P. (1996) "Photoelastic study on the mechanical properties of fractal rock joints", Fractals 4(4), 521-531.

Xie, H., Wang, J.A. and Xie, W.H. (1997a) "Photoelastic study of the contact mechanics of fractal joints", Int. J. Rock Mech. Min. Sci. Geomech. Abstr. 34(5), 865-874.

Xie, He, Wang, J.A. and Xie, W.H. (1997b) "Fractal effects of surface roughness on the mechanical behavior of rock joints", Chaos Solitons Fractals 8(2), 221-252.

Yu, G. (1997) Application of Fractal and Damage Mechanics in Mining Subsidence: [Degree paper] (Beijing Graduate Faculty, China University of Mining and Technology, Beijing).

Yu, G. and Yu, L. (2000) The Nonlinear Theory Measurement and Control in Strata Subsidence (Jilin University Press, Changchun), p 9.

Yu, G., Xie, H. and Wang, J. (1996) "Inquiry into the fractal character of geological disruption plane", J. China Coal Soc. 16(5), 459-463. 


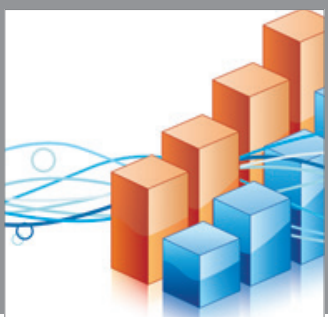

Advances in

Operations Research

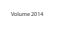

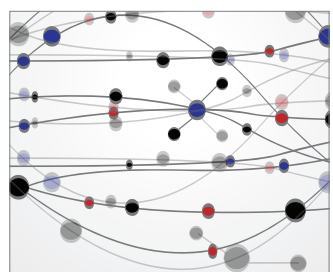

\section{The Scientific} World Journal
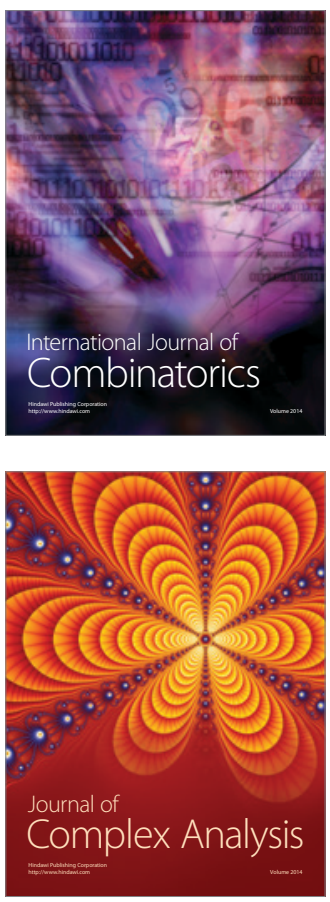

International Journal of

Mathematics and

Mathematical

Sciences
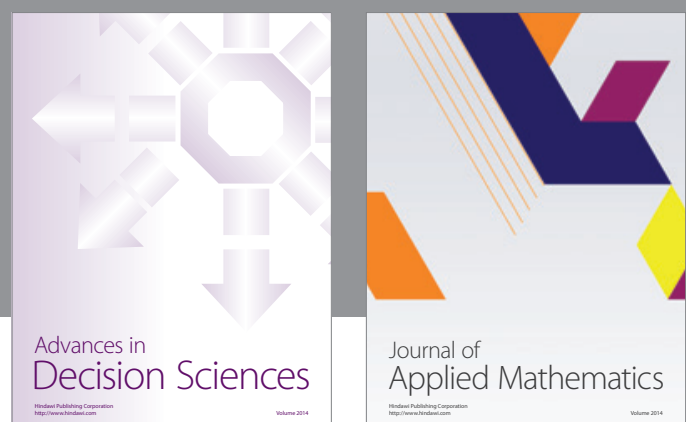

Journal of

Applied Mathematics
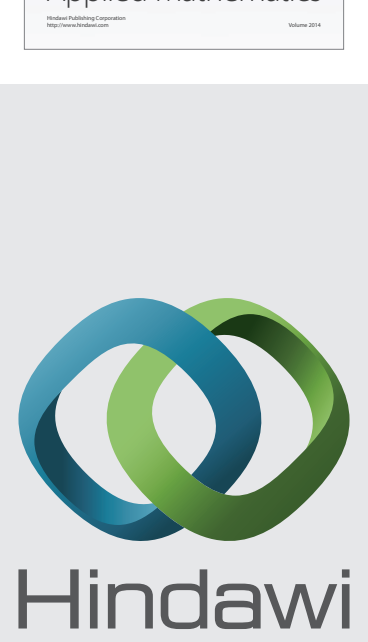

Submit your manuscripts at http://www.hindawi.com
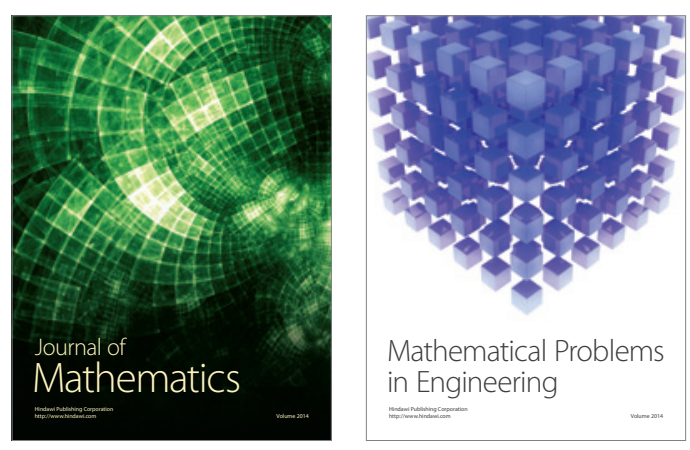

Mathematical Problems in Engineering
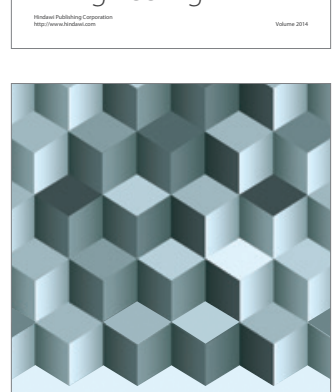

Journal of

Function Spaces
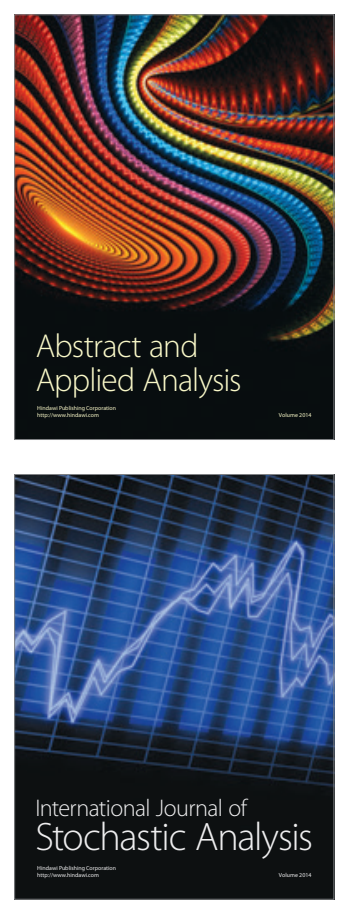

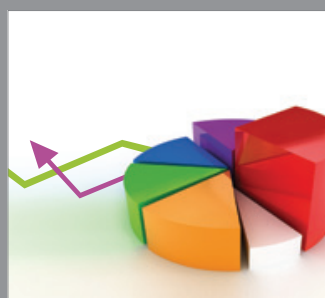

ournal of

Probability and Statistics

Promensencen
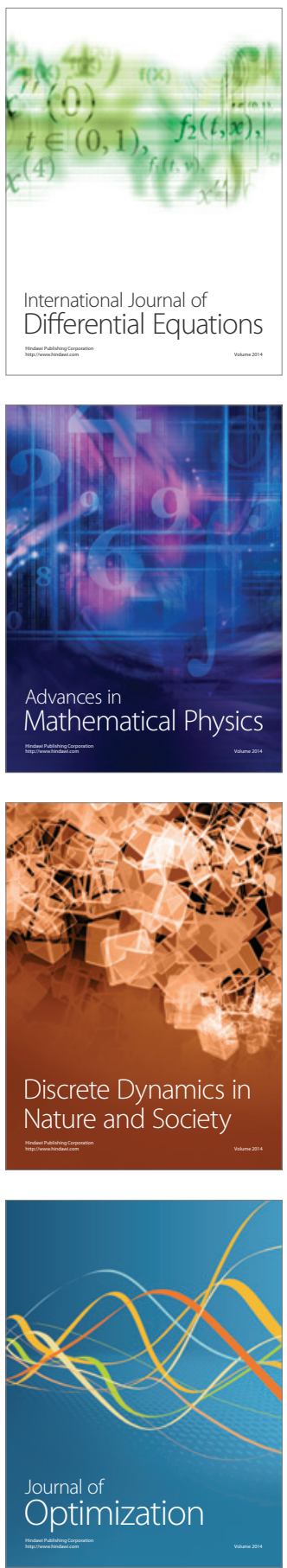